\title{
Farmers's Choice to Risk Management Strategies of Corn Farming in Sigi District Central Sulawesi
}

\author{
Heni SP Rahayu ${ }^{1,{ }^{*}}$, Mardiana Dewi ${ }^{1}$, Tina Febrianti ${ }^{1}$ \\ ${ }^{1}$ Assessment Institute for Agricultural Technology Central Sulawesi
}

\begin{abstract}
Corn has a very significant contribution in the national economy as one of main food crop commodities. As a strategic commodity, corn has big potency even in covid-19 pandemic time, corn relatively resilient compare to other commodities in Central Sulawesi. However the level of corn productivity will relate to the adoption of technology and the farmers's choices to cope with risk, both production and marketing. Therefore, the study aims to know farmers's choices to corn farming risk management strategies. A survey had been conducted to 75 respondents across the three districts in Sigi Central Sulawesi, and a quantitative analysis approach was applied in the study. Data were analyzed using descriptive and multinomial logit analysis. The result showed that mostly of the corn farmers have no spesific risk management strategy due to the limit of information and awareness. While a second number already aware but not use spesific strategies. The rest of respondents have adopted certain strategies for managing risk but not compensatory for marketing's risk yet. Some farmers gave credence to engage with the not formal contract or middleman as buyers and supplier for the production input and thus, becoming vulnerable position for the farmers. Variables that significantly gave effect on the choice of risk management strategies are: education, farm size, activity in farmer group, alternative commodity, and propensity to take a risk.
\end{abstract}

\section{Introduction}

Corn is one of main food crops in Indonesia which has important role in the economy. Corn has multifunctions as raw material of livestock feed industries especially poultry feed, as raw material of food industries such as mayzena flour, corn oil, corn sugar, and biofuel alternatives [1]. Corn is also used for food consumption particularly in east part area of Indonesia. Due to its large function, as Indonesian population growth rapidly every year, the need of corn also sharply increased. Therefore, the production and productivity shall go after the increasing of market demand curve. Following to the dynamization of the demand, corn prominently shown growth number production and has significantly contribution to the national economic in the latest ten years [2].

\footnotetext{
${ }^{*}$ Correspondence email: sulistyawati79@gmail.com
} 
In Indonesia, corn largely produced by small and medium scale of farms. Corn become an agricultural sources income of rural farmers after rice and plantation. Based on its function and contribution to farmer income, corn has important role in the Indonesia economy. For that reason Indonesia government has important program for developing food crops namely SLPTT, UPSUS, and other strategic programs from Ministry of Agriculture. Those programs aim to raise the production and productivity of food crops in order to get self sufficiency [3]. However, the raising productions not always followed by the raising of productivity. It happened in Central Sulawesi Province which shown that the productivity level of corn is relatively stagnant $[4,5]$. However productivity related to many factors such as climate change, technology adoption, and farm management.

The farm management comprises of making and implementing decisison for maximum production and profit a farm [6]. This includes farmer's behavior toward agricultural risk. Producers of agricultural commodities usually have challenges on price and production risk [7]. Generally farms have two types of risks namely production risk and market risk. Risks on corn production such as drought, plant pests and diseases attackment, which can be reduced by proper use of technology and agricultural insurance. While market risks are more difficult to be solved since they are depending on fluctuaction of supply and demand of commodities both domestic and global markets. No significant action yet as hedge or a technique to reduce or eliminate the marketing risk, for example taking position that will offset each other if prices change or to enclose or bound the losess. The marketing risks mostly caused by a sharp fluxtuaction in the prices and an existing asymmetry of information during harvest and marketing period [8]. The lack or excess production generates imbalance in supply and demand which caused the fluctuaction of prices. Furthermore, the revenue will not commemsurate in covering the costs. The strategies to cope the risk both production and marketing become important aspect to take decision in farm management.

Therefore, the study aims to know farmers's choice to corn farming risk management strategies. It is also expected to generate recommendation for decision maker regarding the choice of risk management strategies for farmers, particularly those who grow corn. Moreover, it is expected that in the future there will be a policy recommendation for the government in developing corn agribusiness in Sigi District.

\section{Methodology}

\subsection{Time, Location, and Sampling}

Primary and secondary data were employed in the study. Data gathering for primary data were implemented on 75 respondents of farmers while secondary data were collected from Central Bureau of Statistics Central Sulawesi and other related stakeholder. The study used simple random sampling with purposive location in Sigi District which covered three Sub-district Dolo, Dolo Barat, and Gumbasa from August 2019 to July 2020.

\subsection{Data}

Primary data were collected from respondents who involved in corn agribusiness from production to marketing. Respondents assigning method used purposive sampling which intentionally choose corn farmers and parties who involved in corn farming or marketing such as traders in village and big traders in city. Secondary data were compilled from Central Bureau of Statistics, Sigi District of Agriculture Service, and Central Sulawesi of Agriculture Service. 


\subsection{Multinomial logit model}

A model to look into relationship between binary or ordinal responses probability and explanatory variabels usually use logistic regression analysis [9]. The techniques of logistic regression are used when the outcome variable presents it self in a qualitative way and is represented by one or more dummy variables, depending on the number of possible answers (categories) for this dependent variable. In the condition of research presents more than two categories such as in this study, we should use the multinomial logistic regression. $[10,11]$.

The proper logistic regression deals with more than two categories of responses is multinomial logistic which $\mathrm{Y}$ is the dependent variable with three responses: $\mathrm{Y}=0, \mathrm{Y}=1$, $\mathrm{Y}=2$ or even more. The three possible responses grouped for term of choice of risk management consist: are not aware to the risks and do not use any strategy $(Y=0)$; aware but not use any spesific strategy $(\mathrm{Y}=1)$; aware and use risk management strategies $(\mathrm{Y}=2)$. The independent variables were: age of farmer (age), education (edu), farmer experience (f-exp), farm size (f-size), household size (h-size) active in farmer group (fg_act), alternative income (alt-inc), price information (price-inf), propensity to take a risk (prop-risk), absence of risk perception (abs-risk prep), and production (prod).

The multinomial logit model using the following equation:

$$
\begin{aligned}
\log \left[\frac{Y=\frac{j}{x}}{Y=\frac{j}{x}}\right]= & \beta 1+\beta 2 \text { age }+\beta 2 \text { edu }+\beta 3 \mathrm{f} \text {-exp }+\beta 4 \mathrm{f} \text {-size }+\beta 5 \text { h-Size }+\beta 6 \text { fg_act }+\beta 7 \text { alt- inc } \\
& +\beta 8 \text { price-inf }+\beta 9 \text { prop-risk }+\beta 10 \text { abs-risk prep }+\beta 11 \text { Y-prod }+\mu \mathrm{i}
\end{aligned}
$$

Where: $j=0,1$ and 2; are not aware to the risks and do not use any strategy $(\mathrm{Y}=0)$; aware but not use any spesific strategy $(\mathrm{Y}=1)$; aware and use risk management strategies $(\mathrm{Y}=2)$.

The formula of the marginal effect of each variable:

$E M=\beta P i(1-P i) a s P i=\frac{e^{\beta X}}{1+e^{\beta X}}$

\section{Result and Discussion}

\subsection{Farmers and farms}

Mostly farmer plant various of commodity except corn, such as cocoa and vegetables includes long bean, spinach, and tomato while some farmer put corn farming as the only source of livelihood. The young people usually have less interest in agriculture and make it as a supportive activity while the elderly have it as their living. The survey shows that corn farming is practiced by farmers in average 44 years old. Level of education is important factor in understanding of technology in agriculture practices from cultivation to post harvest which related to management risk strategies. The survey shows that education average is 9 years or junior high school level. The number of years that farmers produce corn the average number was 14,5 years. The corn production done by families including the wives.

The result of descriptive analysis shows that $24 \%$ of respondents took corn production as the only crop, followed by $41.1 \%$, who have variety in commodity including livestock such as cow and chicken. Most farmers (about 96.3\%) reported agriculture as a main source of income, while the rest about $4.7 \%$, stated its not a the primary source. Agriculture especially corn farms become the main source of income is explained largely by the fact that, 
Sigi is a district where experienced earth quake and its irrigation got damaged. Thus corn as a commodity which relatively tolerant with dry land become an option to be developed.

Corn farms in the research area mainly implemented from generation to generation. The risk management strategies occasionally were learnt from the previous generation. Based on this culture, eventhough farmers are not satisfied with the income because of the risk, they do not stop working in agriculture. The reason is that the revenue assist farmers to obtain covering major family expenses, such as daily life. A few farmers considered corn farms as not main source of income, because they have other works as the main activity or have other businesses thus corn production become supportive income.

\subsection{Risk management}

Risk is defined as change and possibility of losing, variability, different actual results from expected results [12]. Farming usually face of risks caused by uncertainties of weather that generates some disasters such as periods heavy rainfall or drought which also can increase pest or diseasases incidents. The result of data analysis shown that some risk which faced by farmers were climate change and price fluctuaction, pests and diseases.

The capability of farmers in handling both production and marketing risks are generally have good financial return. One of the common strategy is the agreements with other parties which mostly informal. The formal agreement not directly contact with the farmers but through the third party. The background is the less quantity of production individually. Usually the third parties will take a part on the channel such as the middleman. The business work using experience and production capacity at the first place. However the contract with the enterprises generally only based on the production quantity and not the price. Different with future contract which developed in developed countries which set the price in the contract. Thus the price risk have not been solved by these agreement. Contract between farmers and the third party usually are informal contract.

Regarding risk identification, a substantial of references has underlined the significance of price uncertanty in commodity supply chains. [16] Noted that the prices of agricultural commodities have become unstable latterly, which make market participants experiencing strains in their business? Managing techniques in commodity risks become a main topic of the current scientific papers. Some important references such as a handbook [17] provides the essentials for understanding risk management. With a prominence on financial derivatives, [18] have provided significant analysis of the risk management. The paper [19] studied the benefit of enclosing operations for the Uruguayan guided in the futures market of the Brazilian livestock in regard to risk and income. [20] Investigated about the bounding strategies for the energy alternatives.

The extent to which a risk is systemic depend on how it can be managed [13]. [14] Distinguished risk strategies into three categories; reduction, mitigation and coping. Risk reduction means limiting the occurrence of undetermined incidents which would negatively influence to farmer's welfare. Risk mitigation includes cut down the negative impact on incidents which arise. Risk coping deal when incidents of risk has occurred or usually means diminishing cost to deal with negative effect on welfare.

The result of study shows that various choices for risk management strategies are applied by farmers. Risk production can be reduced by agronomic and socio economic strategies. Some agronomic strategic namely: delaying planting time, changing the crop variety, water management, and other farming practices, while the socio economic strategies are using indigenous knowledge, accessing to credit source, crop insurance, crop diversification, and off-farm income [15]. 
The agriculture insurance as one risk production solution. The insurance coverage for drought, flood, and pest and plant disease attackment which needs procedures [21]. The low premium in agricultural insurance is affordable for farmer. However it is applicable only for rice and not yet available for corn in Central Sulawesi. The credit has mechanisms which not all farmer could access it. Thus one of strategic by some farmers to deal with the risk is informal contract with the middleman.

The middleman have an important role in marketing to distribute product from farmer as producer to consumers. However, the middlemans have no power for stabilizing the price fluctuations in the market. Beside their main role of selling the products, middlemands also have other business with farmers such as giving the loan for farmers so that they will be engaged with the middleman. The middleman wil give loan if farmer have difficulty such as failed harvesting. The middleman work system is buy the farmer harvest while farmers has taking debt or input factors from them. The debt payment is later after harvest. The middleman cut the price of buying based on the loan. The cut price sometimes over the loan which $\mathrm{n}$ if it over of the loan. Thus a big loss for the farmer however farmers always in weak position, because if they do not engaged with the middleman they would not get the production factors capital.

Price risk management are mainly applied by developed countries where the market's infrastructures already advanced. It provide effective ways to agricultural commodities market challenges [22]. At the same time, agricultural commodities in developing countries such as Indonesia are still struggling with market risks. Hedging in the commodity risk management is also investigated in the paper [23]. The authors compared three basic hedging techniques namely commodity futures, forward and option contracts. In some area of Indonesia, the future contract are applied but in order to get income earlier, and does not be used to eliminate the fluctuactive price. The reason is the low bargaining position of farmers. The optimum future contracts comes down to the buying or selling of future contract value similar to that of the given business, so that a possible loss due to fluctuation in prices is offset by a gain on the futures market. which in addition to this factor, generally does not have adequate conditions for storage and prefers to sell at a low price to avoid incurring costs or losses. Further more it is commonly happpened $\mathrm{n}$ rural area is the lack of information and communication tool of farmers. Marketing as a procees in delivering product from producer to consumers. The price transfered was not correctly received by the farmers.

\subsection{Econometric analysis}

Generally the model were statistically significant which shown in Table 1.

Table 1. Overal test fitting model of risk management strategies

\begin{tabular}{|l|c|c|c|}
\hline & $\begin{array}{c}\text { Model fitting } \\
\text { critera }\end{array}$ & Likelihood ratio test & \\
\hline Model & -2 Log Likelihood & Chi-Square & Sig. \\
\hline Intercept only & 64.391 & & \\
\hline Final & 17.325 & 62.67 & .000 \\
\hline
\end{tabular}

The results of the calculation about the fitting criteria model indicate that the value of $2 \mathrm{LL}$ in the final model is smaller than $-2 \mathrm{LL}$ in the intercept only model. This proves that the model is acceptable. Or in other words, the first hypothesis states that each variable has an effect either jointly or separately. However from eleven variables only four were significant which are as follows: education,farm size, alternative commodity, propensity 
to take a risk. The results of estimation multinomial logit model of risk management strategies shown in Table 2.

Table 2. Significance of variables on multinomial logit model estimation to corn farming risk management strategies

\begin{tabular}{|l|c|c|}
\hline \multicolumn{1}{|c|}{ variables } & Coefficient & Significance \\
\hline Education & 0.8705 & 0.0033 \\
\hline Farm Size & 0.4647 & 0.0028 \\
\hline Alternative commodity & 1.7917 & 0.0000 \\
\hline Propensity to take a risk & 1.8449 & 0.0001 \\
\hline Active farmer group & 1.9866 & 0.0036 \\
\hline
\end{tabular}

Level of education or educational attainment was statistically significant at $5 \%$ which mean that significantly contributed to risk management strategies. The informations including on risk management are easier to be disseminated to farmers with higher educational attainment. Furthermore, education also related with knowledge which it is an intellectual ability and memory in applying concepts to problem solving in the field [24, 25]. The higher of the level education of the farmer, the easier it will be to understand and accept innovations that are delivered to them. Whether farmer can count and calculate the risk they will choose the better strategies.

Farm size is significant in the choose of risk management strategies. Based on the value of the probability that farmers with larger farm size are more concern with the choice of management strategies. However, the increase in farm size in productive areas will be limited by competition with other commodities. Another challenge is that small-scale farmers with land areas below 0.5 ha are dominant in the study area. These farmers have limited capital to increase their land size [26]. The alternative commodities not only a factor but also the startegy itself. When there are losses in production, the alternative commodity still can be used as household expenses.

Membership and activity in farmers' group is significant and positive indicating that being a member of a farmer's group become factors to the choice of risk management strategy. . Farmers who are members of the group have access to the subsidy extended by the government. Other benefits from becoming a member of the farmers' group include the access to information which is expected to decrease risk. The information increases the knowledge of the farmer in managing their farm. However in some cases, it was also observed that the benefits of being a member of farmer's group were not optimally utilized by the farmers. Farmers use the group just for the subsidy and less in getting farming knowledge and guidance. The need of the strong farmer group, in these case farmer still basically involved to farmer group in order of getting program and not for actively engaged in the organization.

Propensity to take a risk is a factor to choose the strategies. The propensity to take a risk also related with other factors. When the propensity to take a risk is higher, the effort in using strategies include reduction, mitigation, and coping also higher [14]. However the education also involve in propensity to take a risk because farmers will take a risk by knowledge and calculation. Asked how far the increased of variabels influence the farmers's choice to risk management stategy can be counted by its marginal effect where shown in Table 3.

Table 3. Marginal effect of estimation multinomial logit model of risk management strategies

\begin{tabular}{|l|c|}
\hline \multicolumn{1}{|c|}{ Variables } & Marginal effect \\
\hline Education & 0.0019 \\
\hline Farm Size & 0.0603 \\
\hline Alternative commodity & 0.2416 \\
\hline Propensity to take a risk & 0.0916 \\
\hline Active farmer group & 0.0564 \\
\hline
\end{tabular}


The interpretation of the marginal effect obtained from the research results shown in the table 3 is as follows: the marginal effect coefficient is the change in the risk management strategies as a result of one unit change in the explanatory variable. This means that the change in the value of explanatory of one unit will increase the choice strategy management. From the table above it can be interpreted that when the education increases by one year/level, there is 0,0019 increase of the probability level choice of strategy. It also applied for farm size, alternative commodity, propensity to take a risk, and the activity in farmers groups which increasing one unit of variabels will increase the choice of risk management strategy.

\section{Conclusion and Recommendation}

The result showed that majority of the corn farmers claimed to use no risk management strategy in due to the lack of information and awareness. While a second number gave credence to engaged with the not formal contract or middleman as buyers and supplier for the production input and thus, becoming vulnerable position from the farmers. The rest of respondents have adopted certain strategies for managing risk but not compensatory for price risk yet. Variables which have statistically significant effect to the risk management strategies are: education, membership in a farmer groups, the alternative comodity, and propensity to the risk.

The government with all related stake holder should disseminate more information about risk mitigation in the extension program and take a risk management strategies as part of technology recommendation. The role of farmer group or other organization such as cooperative should be developed as third parties in developing market system of commodities.

Acknowledgment goes to Dr. Ir. Fery Fahruddin Munier, M.Sc as the Head of Central Sulawesi Assessment Institute for Agricultural Technology (AIAT) for supporting the study.

\section{References}

1. Suryana, A and Agustian, A. Competitiveness Analysis of Corn Farming in Indonesia. Agriculture Policy Analysis. 12 (2): 143-156. (2014)

2. CBS. Central Sulawesi in Number. Central Bureau of Statistics Central Sulawesi. Palu. (2018)

3. Ministry of Agriculture. Ministry of Agriculture Strategic Planning YEAR 2014-2019. Ministry of Agriculture. Jakarta (2015)

4. Rahayu, HSP and Suwitra, IK. Dynamization of Main Crop Productivity in the Acceleration of Food Self-Sufficiency Program. Proceeding. Seminar Sustainable Agriculture Resource in Supporting Food security in The 4.0 Industry Revolution Era. University of Sebelas Maret. p:89-96 (2018)

5. Central Bureau of Statistics. Central Sulawesi in Number. Central Bureau of Statistics Central Sulawesi. Palu (2017)

6. Olson, K. Farm Management: Principles and Strategies. Book. Wiley-Blackwell. 429p (2003)

7. Parcell. J and Pierce, V. Introduction to Hedging Agricultural Commodities with Futures. MU Extension University of Missouri-Columbia (2011) 
8. Zidora, C., Cunha, CA., Neto, OJO., Wander, AE. Price risk management strategies in corn marketing in rural Mozambique. Research Journal of Agriculture and Environmental Management. 5 (5) p: 160-171 (2016)

9. Stefan, Trueck Svetlozar T., Rachev. Rating Based Modeling of Credit Risk Theory and Application of Migration Matrice. Academic Press (2009)

10. Fávero, LP and Belfiore, P. Data Science for Business and Decision Making._Binary and Multinomial Logistic Regression Models. Academic Press. P:539-615 (2019)

11. Hosmer, DW and Lemeshaw, S. Applied Logistic Regression. Second Ed. A Wiley Inter-Science Publication. 397p. (2015)

12. Rondhi, M., Aji, JMM., Khasan AF., Putri, ATR. Yanuarti, R. Risk Aversion, Risk Preference and Farmers' Decision to Participate in Broiler Contract Farming: A Case Study in Jember, Indonesia. Caraka Tani: Journal of Sustainable Agriculture. 35(1), 98107 (2020)

13. Tangermann, S. Risk Management in Agriculture and the future of the UE's common Gricultural Policy. International Centre for Trade and Sustainable Development. Issued Paper: 34. 50p. 2011

14. Breen, B., Hennessy, T., Donnellan, T., Hanrahan, K. Tools and polices for agricultural risk management. Rural Economy and Development Programme, Teagasc (2013)

15. Rahayu, HSP and Suwitra, IK. Agronomic and social strategies on food crop production for climate change adaptation at Palu Valley, Central Sulawesi, Indonesia. IOP Conference Series: Earth and Environmental Science. 8p. (2019).

16. Banterle, A and Vandone, D. Price Volatility and Risk management: The Case of Rice. International European Forum on System Dynamics and Innovation in Food Networks Austria. (2013).

17.Labuszewski J.W., Nyhoff J.E., Co R., Peterson P.E.: The CME Group Risk Management Handbook: Products and Applications. Wiley, New York (2011)

18. Geman H. Risk Management in Commodity Markets:From Shipping to Agriculturals and Energy. The Wiley Finance Series, Wiley, West Sussex (2012)

19. Odilon Jose de O.N., Fabio Gallo G. The cross hedging for the Uruguayan steer in the future market of the Brazilian live cattle: The expectancy hypothesis and speculation on the basis.) Agroalimentaria, 20: 87-105 (2014)

20.Leoni P., Vandaele N., Vanmaele M. Hedging strategies for energy derivatives. Quantitative Finance, 14: 1725-1737 (2013)

21. Pasaribu, S. The Application of Agriculture Insurance in Indonesia. Policy Reformation Toward Agriculture Development Transformation. Jakarta: IAARD Press p: 491-514. (2014)

22. Janchum, N., Witoonpan, S., Cheewaviriyanon, C. Price Risk Management Strategies in Commodity Markets. Journal of Management Sciencies. 4 (2)p.

23. Taušer J., Čajka R. Hedging techniques in commodity risk management. Agricultural Economics - Czech, 60: 174-182 (2014)

24. Kartono. Increasing knowledge of fruit seedling extension through training. Proceeding. IAARD PRESS. Bogor (2015)

25. Basrowi dan Siskandar. Study Evaluation Based on Performance. Karya Putra Darwati. Bandung (2012)

26. Nahraeni, W. Efficiency and Sustainable Value of Horticulture Farming in High Land of West Java. Dissertation. Bogor Agriculture Institute. Bogor (2012) 